\title{
Clinical Outcomes of Hydrogel Spacer Injection Space OAR in Men Submitted to Hypofractionated Radiotherapy for Prostate Cancer
}

\author{
PIETRO PEPE $^{1}$, MARIA TAMBURO $^{2}$, MICHELE PENNISI $^{1}$, DARIO MARLETTA $^{2}$ and FRANCESCO MARLETTA ${ }^{2}$ \\ ${ }^{1}$ Urology Unit, Cannizzaro Hospital, Catania, Italy \\ ${ }^{2}$ Radiotherapy Unit, Cannizzaro Hospital, Catania, Italy
}

\begin{abstract}
Background/Aim: To evaluate the clinical outcomes of men with prostate cancer (PCa) submitted to hydrogel spacer injection before hypofractionated radiotherapy (HRT). Patients and Methods: From April 2018 to April 2020, 32 patients with clinically localized PCa underwent hydrogel injection Space OAR before HRT to the prostate and seminal vesicle; the prescription dose was 60 Gy in 20 fractions, 5 days/week over 4 weeks. PSA levels, genitourinary (GU) and gastrointestinal (GI) toxicities, and sexual function were prospectively evaluated. Results: PSA levels at the median follow up of 15 months was $0.52 \mathrm{ng} / \mathrm{ml} ; 28.1 \% \mathrm{vs} .78 .1 \%$ patients had GI vs. GU Grade 0 acute toxicity and $93.7 \%$ vs. 0\% had GI vs. GU Grade 0 late toxicity. Furthermore, $88.1 \%$ of patients kept pretreatment sexual potency. Conclusion: The use of the hydrogel Spacer OAR before HRT is useful for reducing acute and late $G U$ and GI toxicities.
\end{abstract}

Prostate cancer (PCa) is the second most commonly diagnosed male malignancy (1) in the Western world; radical prostatectomy and external radiotherapy (RT) are currently recommended as definitive treatment alone or combination in men with organ confined, locally advanced and oligometastatic prostate cancer (PCa). In the last years, the advances in physics, engineering and imaging have been channeled into the development of image-guided intensitymodulated radiotherapy that has shown that increasing dose improves biochemical disease-free survival with acceptable acute and long-term toxicities $(2,3)$. In addition, recently,

This article is freely accessible online.

Correspondence to: Dr. Pietro Pepe, Urology Unit - Cannizzaro Hospital, Via Messina 829, Catania, Italy. Tel: +39 957263285, Fax: +39 957263259, e-mail: piepepe@hotmail.com

Key Words: Hydrogel spacer, Space OAR, intraprostatic fiducials, hypofractionated radiotherapy, prostate cancer. the use of a hydrogel spacer (Space OAR) between the rectum and the prostate has been approved to reduce rectal toxicity in prostate radiation therapy $(4,5)$.

In this study, the clinical outcomes of men submitted to hydrogel spacer injection followed by hypofractionated radiotherapy (HRT) were prospectively evaluated.

\section{Patients and Methods}

From April 2018 to April 2020, 32 patients (median age: 70 years; range $=58-82$ years) with clinically localized PCa were treated by HRT directed to the prostate and seminal vesicle. The median PSA was $7.7 \mathrm{ng} / \mathrm{ml}$ (range $=4.1-23) ; 13$ patients $(40 \%)$ were at low risk (Grade Group 1), $16(50 \%)$ at favorable intermediate risk (Grade Group 2) and only $3(10 \%)$ at unfavorable intermediate risk (Grade Group 3) (6); moreover, all patients were without evidence of disease spread to the lymph nodes or the bones. The median prostate volume was $68.3 \mathrm{~cm}^{2}$ and the most frequent comorbidities are reported in Table I. PCa diagnosis was previously performed by transperineal extended prostate biopsy (median 20 cores) $(7,8)$ combined with targeted cores (4 cores) of multiparametric magnetic resonance imaging lesions (Prostate Imaging-Reporting and Data System score $\geq 3)$ suspicious for PCa $(9,10) ; 15 / 32(46.8 \%) v s .11 / 32(34.4 \%) v s$. $6 / 32(18.8 \%)$ patients underwent initial $v s$. repeat $v s$. confirmatory biopsy (men enrolled in active surveillance protocol) (11).

All patients were selected for a hydrogel injection Space OAR before HRT; the injection of hydrogel was performed under sedation by transrectal ultrasound guidance. First, the dissection of the space between Denonvilliers' fascia and the anterior rectum wall was performed with $5-15 \mathrm{ml}$ of saline, then $10 \mathrm{ml}$ of hydrogel were injected (Figure 1A) by a transperineal approach; furthermore, three gold fiducials were inserted transperineally at the prostate base and mid-gland (Figure 1B).

Patients were simulated 2 weeks after placement and abdominal computed tomography (CT) simulation was performed in the supine position with full bladder and empty rectum. These physiological conditions were maintained in all treatment fractions. CT simulation was obtained at $3 \mathrm{~mm}$ slice thickness using an immobilization device, extending from $\mathrm{L} 1$ to below the ischial tuberosities. CT simulation was preceded by MRI simulation in the treatment position. CT-MRI image registration was accomplished using the MIM-software (Maestro, version 7.0.5, MIM Software Inc., Cleveland, OH, USA). 
The whole prostate and seminal vesicle were delineated as the clinical target volume (CTV). Non-uniform planning target volume (PTV) was defined by adding margins to CTV; the margin was 8 $\mathrm{mm}$ in the anterior, lateral, superior and inferior directions, while it was $4 \mathrm{~mm}$ in the posterior direction.

The rectum, urinary bladder, bowel, femoral heads and penile bulb were contoured as organs at risk. The rectum was delineated from the rectosigmoid flexure to the anus; the treatment planning system was Monaco-Elekta (Elekta AB, Stockholm, Sweden). The prescription dose was $60 \mathrm{~Gy}$ in 20 fractions 5 days/week over 4 weeks, the CTV was planned to receive at least $100 \%$ of the prescription dose and the PTV at least $95 \%$ with maximum dose at CTV $<110 \%$ of the prescription dose.

Dose-volume constraints were: dose given to $30 \%$ of rectal volume $<46 \mathrm{~Gy}$, dose given to $50 \%$ of rectal volume $<37 \mathrm{~Gy}$, dose given to $30 \%$ urinary bladder volume $<46 \mathrm{~Gy}$, dose given to $30 \%$ urinary bladder volume $<37 \mathrm{~Gy}$, dose given to $5 \%$ left/right femoral head volume $<43 \mathrm{~Gy}$. Patients were treated with volumetric modulated arc therapy (VMAT) using the LINAC Sinergy Elekta and pretreatment verification of the prostate was conducted using a kilovoltage cone-beam CT during each treatment session.

Patients were followed every 3 months for 2 years, and thereafter every 6 months. PSA relapse was determined according to the Phoenix consensus definition (nadir PSA value plus $2 \mathrm{ng} / \mathrm{ml}$ ). Genitourinary (GU) and gastrointestinal (GI) toxicities were evaluated following RTOG/EORT score. Acute toxicity was defined as that occurred within 3 months after the initiation of radiotherapy, while late toxicity was observed after 3 months. The sexual function was evaluated before and after RT by International Index of Erectile Function - 5 (IIEF-5) score evaluation.

\section{Results}

All patients tolerated well the injection of Space OAR and completed the HRT treatment. PSA levels at the median follow up of 15 months was $0.52 \mathrm{ng} / \mathrm{ml}$; in detail, the median PSA nadir was $0.355 \mathrm{ng} / \mathrm{ml}$ in 5 patients. Table II shows the acute and late GU and GI toxicities.

Twenty-two (70\%) men reported a normal sexual activity before HRT (median IIEF-5 score: 22; range $=20-25$ ); at a median follow up of 15 months from HRT, 18/22 (81.8\%) men kept pretreatment sexual potency (median IIEF-5 score: 21 ; range $=19-25$ ).

\section{Discussion}

Standard radical radiotherapy has been traditionally performed by a fractionated schedule, using daily dose (4045 fractions). The cell death following ionizing radiation is related to the linear-quadratic model that describes the relationship between cell survival, overall dose, and dose per fraction. The response of tissue to fraction size is described by alpha/beta ratio; the alpha/beta estimate for prostate cancer was 1.5 , while most tumors are reported to have an alpha/beta of 10 . Tissues with lower alpha/beta ratios demonstrated greater sensitivity to hypofractionation (12, 13). Standard external radiotherapy used for the treatment of
Table I. Clinical parameters and comorbidities of patients submitted to Space OAR injection before hypofractionated radiotherapy.

\begin{tabular}{lc}
\hline Patients & $\mathrm{N}(\%)$ \\
& 32 \\
\hline Median age & 70 years (range=58-82) \\
Most frequent comorbidity & \\
Blood hypertension & $20(62 \%)$ \\
Diabetes & $12(37 \%)$ \\
Heart disease & $11(34 \%)$ \\
Initial PSA (ng/ml) median (range) & $7.7(4.1-23)$ \\
ISUP Grade Group 1 (3+3) & $13(40 \%)$ \\
ISUP Grade Group 2 (3+4) & $16(50 \%)$ \\
ISUP Grade Group 3 (4+3) & $3(9 \%)$ \\
Prostate volume median $\mathrm{cm}^{3}$ & $68(44.8-101)$
\end{tabular}

ISUP: International Society of Urological Pathology.

$\mathrm{PCa}$ is associated with $5 \%$ or lower grade 3 toxicity rates, and grade 4 toxicity rates of less than $1 \%$. The HRT refers to the delivery of 2.4-4.0 Gy per fraction daily over 4-6 weeks; it is well tolerated with the obvious economic and practical advantages associated with shorter treatment durations (14). There are three large randomized noninferiority trials (15-17) evaluating the equivalence of hypofractionation with standard treatment; the CHHiP (14), RTOG 0415 (15) and PROFIT (16) studies included patients in different risk groups differing in the use of hormonal therapy; however, all studies showed similar results, demonstrating that the efficacy of hypofractionation is not inferior to standard treatment. They differed in the late toxicity outcomes; RTOG 0415 and CHHiP reported no difference in late toxicity, while PROFIT reported a lower rate of late toxicity in the hypofractionated arm.

Recently, a novel device, Space OAR, has been introduced in clinical practice with the intent to reduce toxicity in patients submitted to radiotherapy (18). The hydrogel is allocated between the prostate and the rectum to separate these two structures and to reduce the dose of radiation delivered to the rectum. The polyethylene glycol-based spacer, Space OAR hydrogel, implanted between the prostate gland and the rectum may significantly reduce the dose received by the rectum and the risk of rectal toxicity (19). Babar et al. (20) in a systematic review showed that Space OAR reduced the radiation dose volume to the rectum over numerous dosimetry levels; in detail, Space OAR significantly decreased acute Grade 1 diarrhea, late Grade 1 and Grade $\geq 2$ rectal toxicities and urinary incontinence. Recently, Applewhite et al. (21) reported that hydrogel spacers can also be effectively used in patients previously submitted to prostate cryoablation who underwent salvage radiotherapy. In addition, the injection of Space OAR reduced significantly rectal dose sparing in men submitted to 
A

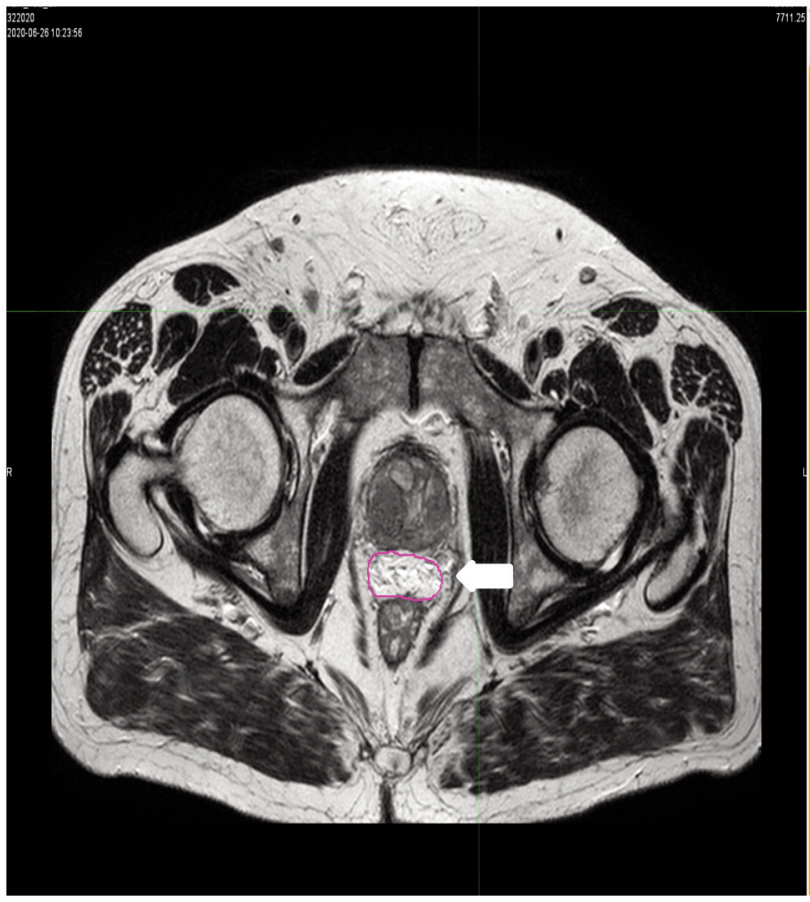

B

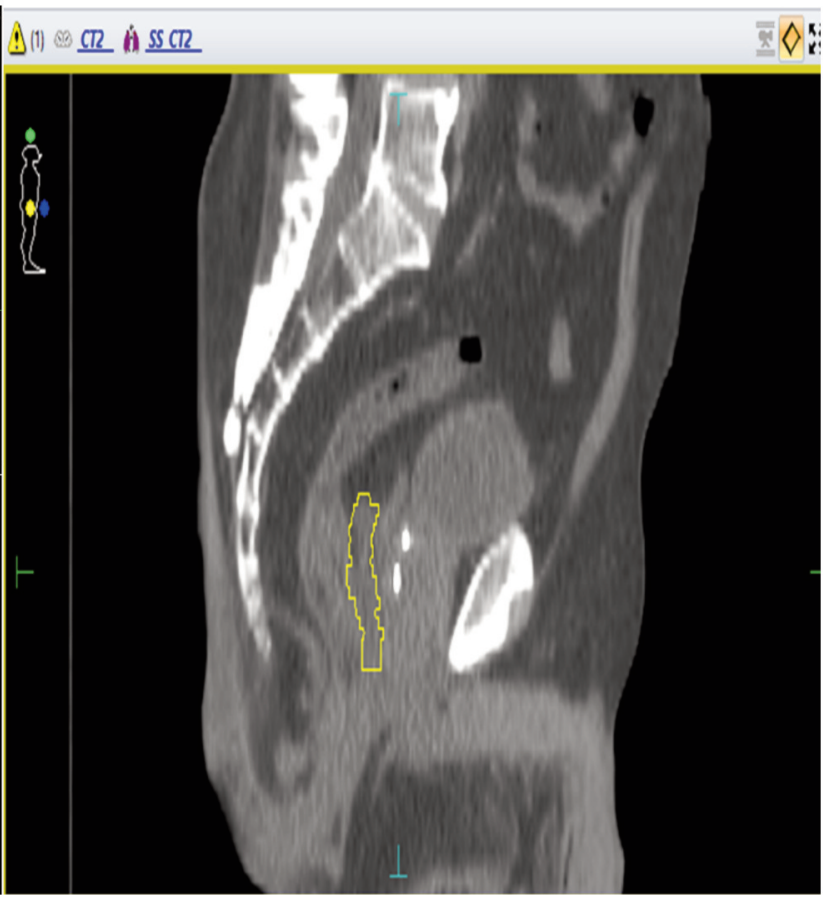

Figure 1. Pelvic magnetic resonance image (A: axial evaluation; B: sagittal evaluation): Hydrogel Space OAR (A) allocated between the prostate and the rectum (white arrow) plus fiducials $(B)$ allocated into prostate.

brachytherapy $(22,23)$. On the other hand, rarely, major complications following Space OAR injection have been reported including, severe anaphylaxis, acute pulmonary embolism, prostatic or perineal abscess and sepsis, rectal wall erosion, and recto-urethral fistula (24).

In our series, the PSA value at median follow up of 15 months was $0.52 \mathrm{ng} / \mathrm{ml}$; 9/32 (28.1\%) vs. 25/32 (78.1\%) had GI vs. GU Grade 0 acute toxicity and 30/32 (93.7\%) vs. 0\% men had GI vs. GU Grade 0 late toxicity. In detail, only 1 (3.1\%) patient reported a GU late complication of Grade 3; moreover, $88.1 \%$ of patients $(18 / 22)$ kept pretreatment sexual potency (median IEEF-5 score: 21 ).

Regarding our results, some considerations should be presented. First, the number of men submitted to Space OAR and fiducials injection is limited. Second, the follow up of the patients is short to evaluate long term oncological results especially in men with intermediate risk PCa. Third, the was no control group. Finally, the cost-effectiveness of hydrogel and fiducials injection should be compared with the reduction of hospital recovery and/or salvage treatment secondary to standard radiotherapy complications.

In conclusion, the use of the hydrogel Spacer OAR before HRT is well tolerated and reduces the incidence of acute and late GU and GI toxicities improving the quality of life of the patients.
Table II. Acute and late genitourinary (GU) and gastrointestinal (GI) toxicity score* in 32 men who underwent Space OAR injection before hypofractionated radiotherapy.

\begin{tabular}{lccrccc}
\hline & \multicolumn{2}{c}{ GU $(\mathrm{n}=32)$} & & \multicolumn{2}{c}{ GI $(\mathrm{n}=32)$} \\
\cline { 2 - 3 } \cline { 5 - 6 } Grade & Acute & Late & & Acute & Late \\
\hline 0 & 9 & 30 & & 25 & - \\
1 & 19 & 0 & & 7 & - \\
2 & 4 & 1 & & - & - \\
3 & - & 1 & & - & - \\
4 & - & - & & - & - \\
\hline
\end{tabular}

*Radiation Therapy Oncology Group (RTOG)/European Organisation for Research and Treatment of Cancer (EORTC).

\section{Conflicts of Interest}

The Authors declare no conflicts of interest regarding this study.

\section{Authors' Contributions}

The Authors contributed equally in all aspects of this article. 


\section{References}

1 Jemal A, Bray F, Center MM, Ferlay J, Ward E and Forman D: Global cancer statistics. CA Cancer J Clin 61(2): 69-90, 2011. PMID: 21296855. DOI: 10.3322/caac.20107

2 Kuban DA, Levy LB, Cheung MR, Lee AK, Choi S, Frank S and Pollack A: Long-term failure patterns and survival in a randomized dose-escalation trial for prostate cancer. Who dies of disease? Int J Radiat Oncol Biol Phys 79(5): 1310-1317, 2011. PMID: 20493642. DOI: 10.1016/j.ijrobp.2010.01.006

3 Dearnaley DP, Jovic G, Syndikus I, Khoo V, Cowan RA, Graham JD, Aird EG, Bottomley D, Huddart RA, Jose CC, Matthews JH, Millar JL, Murphy C, Russell JM, Scrase CD, Parmar MK and Sydes MR: Escalated-dose versus control-dose conformal radiotherapy for prostate cancer: long-term results from the MRC RT01 randomised controlled trial. Lancet Oncol 15(4): 464-473, 2014. PMID: 24581940. DOI: 10.1016/S1470-2045(14)70040-3

4 Whalley D, Hruby G, Alfieri F, Kneebone A and Eade T: SpaceOAR hydrogel in dose-escalated prostate cancer radiotherapy: rectal dosimetry and late toxicity. Clin Oncol (R Coll Radiol) 28(10): e148-e154, 2016. PMID: 27298241. DOI: 10.1016/j.clon.2016.05.005

5 Paetkau O, Gagne IM and Alexander A: SpaceOAR (C) hydrogel rectal dose reduction prediction model: a decision support tool. J Appl Clin Med Phys 21(6): 15-25, 2020. PMID: 32250042. DOI: $10.1002 / \mathrm{acm} 2.12860$

6 Epstein JI, Egevad L, Amin MB, Delahunt B, Srigley JR, Humphrey PA and Grading Committee: The 2014 International Society of Urological Pathology (ISUP) consensus conference on Gleason grading of prostatic carcinoma: Definition of grading patterns and proposal for a new grading system. Am J Surg Pathol 40(2): 244-252, 2016. PMID: 26492179. DOI: 10.1097/PAS.00000 00000000530

7 Pepe P and Aragona F: Saturation prostate needle biopsy and prostate cancer detection at initial and repeat evaluation. Urology 70(6): 1131-1135, 2007. PMID: 18158033. DOI: 10.1016/j.urology.2007.07.068

8 Pepe P, Pennisi M and Fraggetta F: How many cores should be obtained during saturation biopsy in the era of multiparametric magnetic resonance? Experience in 875 Patients Submitted to Repeat Prostate Biopsy. Urology 137: 133-137, 2020. PMID: 31758981. DOI: 10.1016/j.urology.2019.11.016

9 Pepe P, Pepe L, Pennisi M and Fraggetta F: Which prostate biopsy in men enrolled in active surveillance? Experience in 110 men submitted to scheduled three-years transperineal saturation biopsy combined with fusion targeted cores. Clin Genitourin Cancer, 2021. PMID: 33642223. DOI: 10.1016/j.clgc.2021. 01.004

10 Pepe P, Garufi A, Priolo G, Dibenedetto G, Salemi M, Pennisi M, Fraggetta F, Aragona F and Barbera M: Accuracy of 3 Tesla pelvic phased-array multiparametric MRI in diagnosing prostate cancer at repeat biopsy. Arch Ital Urol Androl 86(4): 336-339, 2014. PMID: 25641466. DOI: 10.4081/aiua.2014.4.336

11 Pepe P, Garufi A, Priolo GD, Galia A, Fraggetta F and Pennisi $\mathrm{M}$ : Is it time to perform only magnetic resonance imaging targeted cores? Our experience with 1,032 men who underwent prostate biopsy. J Urol 200(4): 774-778, 2018. PMID: 29679618. DOI: $10.1016 /$ j.juro.2018.04.061

12 Brenner DJ, Hlatky LR, Hahnfeldt PJ, Huang Y and Sachs RK: The linear-quadratic model and most other common radiobiological models result in similar predictions of time-dose relationships. Radiat Res 150(1): 83-91, 1998. PMID: 9650605.

13 Thames HD, Bentzen SM, Turesson I, Overgaard M and Van den Bogaert W: Time-dose factors in radiotherapy: a review of the human data. Radiother Oncol 19(3): 219-235, 1990. PMID: 2281152. DOI: 10.1016/0167-8140(90)90149-q

14 Aluwini S, Pos F, Schimmel E, Krol S, van der Toorn PP, de Jager H, Alemayehu WG, Heemsbergen W, Heijmen B and Incrocci L: Hypofractionated versus conventionally fractionated radiotherapy for patients with prostate cancer (HYPRO): late toxicity results from a randomised, non-inferiority, phase 3 trial. Lancet Oncol 17(4): 464-474, 2016. PMID: 26968359. DOI: $10.1016 /$ S $1470-2045(15) 00567-7$

15 Dearnaley D, Syndikus I, Mossop H, Khoo V, Birtle A, Bloomfield D, Graham J, Kirkbride P, Logue J, Malik Z, Money-Kyrle J, O'Sullivan JM, Panades M, Parker C, Patterson H, Scrase C, Staffurth J, Stockdale A, Tremlett J, Bidmead M, Mayles H, Naismith O, South C, Gao A, Cruickshank C, Hassan S, Pugh J, Griffin C, Hall E and CHHiP Investigators: Conventional versus hypofractionated high-dose intensitymodulated radiotherapy for prostate cancer: 5-year outcomes of the randomised, non-inferiority, phase 3 CHHiP trial. Lancet Oncol 17(8): 1047-1060, 2016. PMID: 27339115. DOI: $10.1016 / \mathrm{S} 1470-2045(16) 30102-4$

16 Lee WR, Dignam JJ, Amin MB, Bruner DW, Low D, Swanson GP, Shah AB, D'Souza DP, Michalski JM, Dayes IS, Seaward SA, Hall WA, Nguyen PL, Pisansky TM, Faria SL, Chen Y, Koontz BF, Paulus R and Sandler HM: Randomized Phase III noninferiority study comparing two radiotherapy fractionation schedules in patients with low-risk prostate cancer. J Clin Oncol 34(20): 2325-2332, 2016. PMID: 27044935. DOI: 10.1200/JCO.2016.67.0448

17 Catton CN, Lukka H, Gu CS, Martin JM, Supiot S, Chung PWM, Bauman GS, Bahary JP, Ahmed S, Cheung P, Tai KH, Wu JS, Parliament MB, Tsakiridis T, Corbett TB, Tang C, Dayes IS, Warde P, Craig TK, Julian JA and Levine MN: Randomized trial of a hypofractionated radiation regimen for the treatment of localized prostate cancer. J Clin Oncol 35(17): 1884-1890, 2017. PMID: 28296582. DOI: 10.1200/JCO.2016.71.7397

18 Hall WA, Tree AC, Dearnaley D, Parker CC, Prasad V, Roach $\mathrm{M} 3$ rd and Lawton CAF: Considering benefit and risk before routinely recommending SpaceOAR. Lancet Oncol 22(1): 1113, 2021. PMID: 33387489. DOI: 10.1016/S1470-2045(20) 30639-2

19 Ung M, Bossi A, Abbassi L, Vautier J, Anthonipillai V, Chevé $\mathrm{M}$ and Blanchard P: [Dosimetric impact of hydrogel spacer use for stereotactic body radiotherapy of localised prostate cancer]. Cancer Radiother 25(3): 237-241, 2021. PMID: 33419606. DOI: 10.1016/j.canrad.2020.09.004

20 Babar M, Katz A and Ciatto M: Dosimetric and clinical outcomes of SpaceOAR in men undergoing external beam radiation therapy for localized prostate cancer: A systematic review. J Med Imaging Radiat Oncol 65(3): 384-397, 2021. PMID: 33855816. DOI: 10.1111/1754-9485.13179

21 Applewhite J, Barker J Jr and Vestal JC: Successful use of absorbable hydrogel rectal spacers (SpaceOAR) before salvage radiation therapy after previous prostate cryotherapy. Adv Radiat Oncol 6(3): 100647, 2021. PMID: 33748548. DOI: 10.1016/j.adro. 2021.100647 
22 Butler WM, Kurko BS, Scholl WJ and Merrick GS: Effect of the timing of hydrogel spacer placement on prostate and rectal dosimetry of low-dose-rate brachytherapy implants. J Contemp Brachytherapy 13(2): 145-151, 2021. PMID: 33897787. DOI: $10.5114 /$ jcb.2021.105281

23 Wu SY, Boreta L, Wu A, Cheung JP, Cunha JAM, Shinohara $\mathrm{K}$ and Chang $\mathrm{AJ}$ : Improved rectal dosimetry with the use of SpaceOAR during high-dose-rate brachytherapy. Brachytherapy 17(2): 259-264, 2018. PMID: 29203149. DOI: 10.1016/j.brachy.2017.10.014
24 Aminsharifi A, Kotamarti S, Silver D and Schulman A: Major Complications and adverse events related to the injection of the SpaceOAR hydrogel system before radiotherapy for prostate cancer: review of the manufacturer and user facility device experience database. J Endourol 33(10): 868-871, 2019. PMID: 31452385. DOI: $10.1089 /$ end.2019.0431

Received June 20, 2021

Revised July 25, 2021

Accepted July 26, 2021 